American Journal of Pharmacology and Toxicology 1 (4): 65-71, 2006

ISSN 1557-4962

(C) 2006 Science Publications

\title{
Therapeutic Effects of Phyllanthus Species: Induction of TNF-a-mediated Apoptosis in HepG2 Hepatocellular Carcinoma Cells
}

\author{
${ }^{1}$ Sripathi M. Sureban, ${ }^{1}$ Dharmalingam Subramaniam, ${ }^{2}$ Paramasivam Rajendran, ${ }^{3}$ Rama P. Ramanujam, \\ ${ }^{4}$ Brian K. Dieckgraefe, ${ }^{1}$ Courtney W. Houchen and ${ }^{1,4}$ Shrikant Anant \\ ${ }^{1}$ Department of Internal Medicine and ${ }^{4}$ Department of Cell Biology \\ University of Oklahoma Health Sciences Center, Oklahoma City, OK \\ ${ }^{2}$ Department of Microbiology, Dr. ALM PG Institute of Basic Medical Sciences \\ University of Madras, Taramani, Chennai, India \\ ${ }^{3}$ Swaasth, Inc., Oklahoma City, OK \\ ${ }^{4}$ Department of Internal Medicine, Washington University School of Medicine, St Louis, MO
}

\begin{abstract}
Phyllanthus species, especially P. amarus is a medicinal plant with hepatoprotective activity, believed to occur in part by inhibiting hepatitis B virus function. The pathogenesis mechanism of viral hepatitis is closely related to hepatocyte necrosis apoptosis. The aim of our study was to investigate the in vitro effects of extracts from three Phyllanthus species, $P$. urinaria, $P$. amarus and $P$. debilis in regulating cell proliferation and gene expression activities of HepG2 hepatocellular carcinoma cells. All three Phyllanthus species significantly inhibited the proliferation of the HepG2 cells. In addition, the extracts induced apoptosis by inducing caspase-3. Further confirmation of extract-induced apoptosis was obtained by demonstrating that the Bcl-2/Bax ratio decreased in response to treatment with the extracts. We next determined the mechanism by which the Phyllanthus extracts induced apoptosis. Previous studies have demonstrated that TNF- $\alpha$ not only induces apoptotic signals but also causes antiapoptotic and regenerative responses in hepatocytes, the mechanism involving induction of IL-8. Real Time PCR analyses demonstrated that the extracts significantly inhibited cyclooxygenase-2 (COX-2) and interleukin-8 (IL-8) expression, while inducing the expression of tumor necrosis factor- $\alpha$ (TNF- $\alpha$. Reporter assays using the luciferase constructs containing COX-2 promoter region demonstrated that the extracts inhibited transcription of the gene. Since the extracts inhibited IL-8 expression, while inducing TNF- $\alpha$, the cells were treated with the extracts in the presence of exogenous TNF- $\alpha$. While TNF- $\alpha$ only showed a modest effect by itself, it was synergistic with the extracts in inducing apoptosis of the cells. These findings demonstrate that Phyllanthus extracts induce TNF- $\alpha$ production from the hepatocellular carcinoma cells while inhibiting production of potent anti-apoptotic genes IL-8 and COX-2.
\end{abstract}

Key words: Phyllanthus species, P. amarus, medicinal plant, hepatocellular carcinoma

\section{INTRODUCTION}

Hepatocellular carcinoma (HCC) is the fifth most common neoplasm, the major cause of death in patients with liver cirrhosis and the third most common cause of cancer-related death in the world ${ }^{[1]}$. Ninety percent of HCC develop in the context of chronic liver disease and mainly in patients with cirrhosis ${ }^{[1,2]}$. Viral hepatitis is the most common cause of HCC worldwide $^{[3]}$ Various treatments are available for $\mathrm{HCC}$ caused by viral hepatitis, some of them include treatment with interferon, tumor necrosis factor (TNF), immunostimulants and various antiviral drugs ${ }^{[4]}$. The limitations of these drugs are that they are not cost effective, numerous side effects and viral mutations resulting in drug resistance especially if the drugs are taken for a long time ${ }^{[5,6]}$. Many of these drugs do not posses anticancer activity ${ }^{[7]}$. Hence, there is a need for alternative therapies for the treatment viral hepatitis and resulting hepatocellular carcinoma.

Herbal remedies having antiviral and anticancer activities are good candidates for the treatment of $\mathrm{HCC}^{[4]}$. Plants of the species Phyllanthus particularly Phyllanthus amarus (P. amarus) have been used by

Corresponding Author: Shrikant Anant, Ph.D. Department of Internal Medicine, Washington University School of Medicine, St Louis, MO Tel: (415) 271-5428, Fax: (405) 271-5450 
traditional medicine practitioners around the world for the treatment of jaundice and other liver diseases. $P$. amarus encodes various activities against viral hepatitis, jaundice, hepatoprotective, immunomodulating and anti-inflammatory activities ${ }^{[8,9]}$. Extracts of $P$. amarus inhibit the interaction between Hepatitis B surface antigen (HBsAg) and an antibody to $\mathrm{HbsAg}^{[10]}$. Hepatitis B virus (HBV) encodes an endogenous DNA polymerase, which is required for replication of the viral $\mathrm{DNA}^{[11]}$. P. amarus inhibits the activity of the HBV DNA polymerase enzyme, suggesting one potential mechanism for antiviral activity $^{[12]}$. $P$. amarus extracts have also been demonstrated to have anti-inflammatory potential because it can inhibit COX-2 and iNOS expression by suppressing the activation of transcription factor $\mathrm{NFkB}^{[13]}$. Other genus of Phyllanthus, including $P$. urinaria and $P$. debilis are also believed to posses hepatoprotective and antiviral activities ${ }^{[14,15]}$. However, the anticancer activity of Phyllanthus extracts, especially of $P$. amarus, $P$. urinaria and $P$. debilis against hepatocellular carcinoma is currently not known.

The present study was designed to investigate the effect of $P$. urinaria, $P$. amarus and $P$. debilis purified extracts on HepG2 human hepatocellular carcinoma cells. The three extracts demonstrated inhibited proliferation of the cells while inducing apoptosis. Furthermore, there was a decrease in the expression of anti-apoptosis gene $\mathrm{Bcl}-2$, while that of proapoptotic gene Bax was increased. In addition, the extracts induced the expression of TNF- $\alpha$, while reducing the expression of COX-2. Inhibition of COX-2 expression was determined to be at the transcriptional level using a luciferase reporter construct. TNF- $\alpha$ is known to encode both pro-apoptotic and anti-apoptotic functions, this being dependent on expression of IL-8 through transcription factor NF-kB. We observed that the extracts inhibited the expression of IL-8. Furthermore, while TNF- $\alpha$ alone did not have a significant effect on HepG2 cells, it synergized with the Phyllanthus extracts to significantly induce apoptosis in these cells. This suggests that one mechanism of restricting the growth of hepatocellular carcinoma cells by the Phyllanthus extracts involves TNF- $\alpha$-mediated apoptosis.

\section{MATERIALS AND METHODS}

Plant extracts: $P$. urinaria, $P$. amarus and $P$. debilis were obtained from Malaysia. Extracts were prepared with $70 \%$ ethanol at $65^{\circ} \mathrm{C}$ for $4 \mathrm{~h}$ in a water bath. The extract was filtered to remove all the impurities and was dried under vacuum. The extracts were reconstituted in dimethylsulfoxide (DMSO) for use in the experiments.

Cell culture and treatment: HepG2 hepatocellular carcinoma cell line was grown at $37^{\circ} \mathrm{C}$ in a humidified atmosphere of $5 \% \mathrm{CO}_{2}$ in sterile filtered Minimum essential medium (Eagle) with $2 \mathrm{mM} \mathrm{L}$-glutamine and Earle's BSS adjusted to contain $1.5 \mathrm{~g} \mathrm{~L}^{-1}$ sodium bicarbonate, $0.1 \mathrm{mM}$ non-essential amino acids and 1.0 $\mathrm{mM}$ sodium pyruvate, $10 \%$ fetal bovine serum (Sigma, St. Louis, MO) and $1 \%$ antibiotic-antimycotic solution (final concentration: $100 \mathrm{U} \mathrm{mL}^{-1}$ penicillin $\mathrm{G}, 0.25 \mathrm{mg}$ $\mathrm{mL}^{-1}$ amphotericin $\mathrm{B}, 100 \mathrm{mg} \mathrm{mL} \mathrm{m}^{-1}$ streptomycin; Mediatech Cellgro, Herndon, VA). Cells were treated with purified $P$. urinaria, $P$. amarus and $P$. debilis plant extracts dissolved in DMSO for the indicated time. The untreated cells (control) received only DMSO (0.01\%), which did not affect the cells.

Apo-ONE ${ }^{\circledR}$ homogeneous caspase-3/7 assay: The HepG2 cells were treated with Phyllanthus extracts for $48 \mathrm{~h}$. Further the cells were subjected to Apo-ONE® Homogeneous Caspase-3/7 assay. The assay provides a fast and sensitive measurement of active caspase- 3 and -7 in a homogeneous format. The assay includes a profluorescent caspase-3/7 consensus substrate, ZDEVD-R110 and an optimized bifunctional cell lysis/activity buffer. The substrate and buffer are combined to make the Apo-ONE ${ }^{\circledR}$ Caspase- $3 / 7$ Reagent that is added directly to the cells treated with or without Phyllanthus extracts. Upon cleavage on the C-terminal side of the aspartate residue in the DEVD peptide substrate sequence by caspase-3/7 enzymes, the rhodamine 110 becomes fluorescent when excited at a wavelength of $498 \mathrm{~nm}$. The emission maximum is $521 \mathrm{~nm}$. The amount of fluorescent product generated is representative of the amount of active caspase-3/7 in the sample, which is a measure of apoptosis of the cells.

Cell proliferation assay (hexosaminidase assay): HepG2 cells were grown in a 96 well microtitre plate (SARSTEDT, Newton, NC) to about $\sim 40 \%$ confluency and treated with plant extracts at a final concentration of $10 \mu \mathrm{g} \mathrm{mL}^{-1}$ for $48 \mathrm{~h}$. Subsequently, a chromogenic substrate (p-nitrophenyl-N-acetyl- $\beta$-D-Glucosaminide) (Sigma) was added to the cells. The lysozyme enzyme (N-acetyl- $\beta$-D-hexosaminidase) released from the proliferating cells convert the substrate to $p$ nitrophenyl, which was measured in a microtitre plate reader (Synergy HT, BIO-TEK, Vinooski, VT) at $405 \mathrm{~nm}$. 
Real time PCR analysis: Total RNA isolated from HepG2 cells treated with the plant extracts for $4 \mathrm{~h}$ was subjected to reverse transcription with Superscript ${ }^{\mathrm{TM}}$ II RNase H - Reverse Transcriptase and random hexanucleotide primers (Invitrogen, Carlsbad, CA).

The cDNA was subsequently used to perform Real Time PCR by SYBR chemistry $\left(\right.$ SYBR $^{\circledR}$ Green I; Molecular Probes, Oregon, USA) for specific transcripts using gene specific primers and Jumpstart Taq DNA polymerase (Sigma). The crossing threshold value was determined for the transcripts and normalized with that observed with $\beta$-actin mRNA. The changes in mRNA expression were expressed as fold change relative to control \pm standard error. Primers used are as follows:

\section{Bcl2: Forward: 5'-TGGATCCAGGATAACGGAGG-3' Reverse: 5'-CAAACAGAGGTCGCATGCTG-3' \\ Bax: Forward: 5'-CCCAGTTGAAGTTGCCATCA-3' Reverse: 5'-TCCCCCCGAGAGGTCTTCT-3' \\ TNF- $\alpha$ : Forward: 5'-GACCCTCAGACTCAGATCATCCTTCT-3' Reverse: 5'-ACGCTGGCTCAGCCACTC-3' \\ COX-2: Forward: 5'- GAATCATTCACCAGGCAAATTG- 3' Reverse: 5'- TCTGTACTGCGGGTGGAACA-3'. \\ IL-8: Forward: 5'-CTCTTGGCAGCCTTCCTGATT-3' Reverse: 5'-TATGCACTGAGATCTAAGTTCTTTAGC-3'. \\ B-actin: Forward: 5'-GGTGATCCACATCTGCTGGAA-3' Reverse: 5'-ATCATTGCTCCTCCTCAGGG-3' and}

Transfection and dual-luciferase reporter gene assay: HepG2 cells were transiently transfected using FuGENE 6 (Roche, Indianapolis, IN) with a firefly (Photinus pyralis) luciferase reporter construct containing 1983-bp (nucleotides -1840 to +143 ) of the promoter region of human COX-2 gene along with the control luciferase construct Renilla pRL-TK (Promega, Madison, WI). The cells were subsequently for $4 \mathrm{~h}$ with the indicated purified plant extracts (final concentration $10 \mu \mathrm{g} \mathrm{mL}^{-1}$ ) and the cell lysates was prepared and subjected to luciferase activity measurement. Luciferase levels were determined as per manufacturer's instructions (Dual-Luciferase ${ }^{\circledR}$ Reporter Assay System, Promega, Madison, WI) using a Monolight 2010 luminometer (Analytical Luminescence Laboratory, San Diego, CA). Luciferase activity was normalized to Renilla Luciferase activity and presented as luciferase units relative to control. Assays were performed in triplicate wells and experiments were repeated 3 times.

Statistical analysis: The data were expressed as mean $=$ SEM. The difference between the treated and control cells was evaluated by student's t-test.

\section{RESULTS AND DISCUSSION}

Effect of phyllanthus extracts on HepG2 cell proliferation: HepG2 cells were treated with $10 \mu \mathrm{g}$ $\mathrm{mL}^{-1}$ of $P$. urinaria, $P$. amarus and $P$. debilis extracts for $48 \mathrm{~h}$ to determine whether they affected the proliferation of these cells. All three extracts significantly inhibited cell proliferation, with highest level of activity observed with extracts from $P$. debilis $(\mathrm{p}<0.05)$ (Fig. 1A). Lower levels of proliferation inhibition were observed in the presence of extracts of $P$. urinaria $(18 \%, \mathrm{p}<0.05)$ and $P$. amarus $(15 \%$, $\mathrm{p}<0.05$ ) (Fig. 1A). These data suggest that Phyllanthus extracts can suppress the active division of the cells.

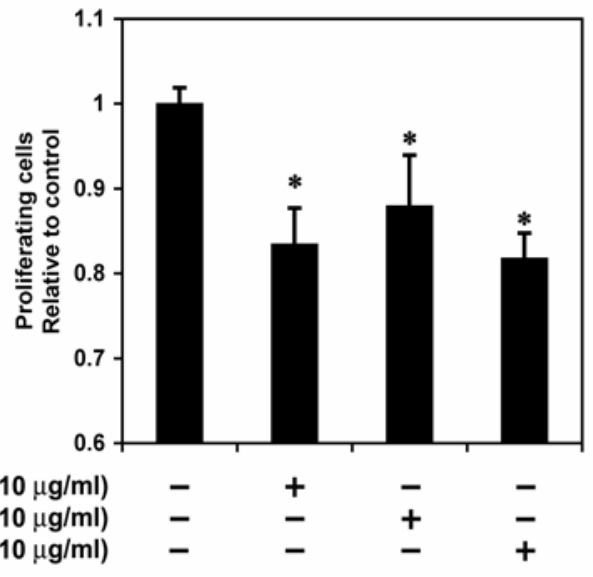

Fig. 1: Effect of Phyllanthus extracts on HepG2 cell proliferation. Extracts of $P$. amarus, $P$. urinaria and $P$. debilis were incubated at a final concentration of $10 \mu \mathrm{g} \mathrm{mL}^{-1}$ and its effects on cell proliferation were determined. Proliferation activity is expressed as a fold change when compared to vehicle-treated control. Data shows that all three Phyllanthus extracts inhibited HepG2 cell proliferation

Phyllanthus extracts inhibit expression of proliferation-related genes: Prostaglandins are involved in many aspects of carcinogenesis, including tumor growth and development and in inhibiting apoptosis ${ }^{[16]}$. Cyclooxygenase (COX) is the ratelimiting enzyme in prostaglandin synthesis and the expression is significantly induced by various mitogens and inflammatory ligands including TNF- $\alpha^{[17]}$. COX-2 expression is also significantly increased in hepatocellular carcinoma cells and targeting it with specific inhibitors has been proposed to be a viable therapeutic option for $\mathrm{HCC}^{[16,17]}$. To determine whether Phyllanthus extracts affected COX-2 expression in HepG2 cells, total RNA from the cells treated with the three extracts were subjected to real time RT PCR for COX-2 mRNA. 


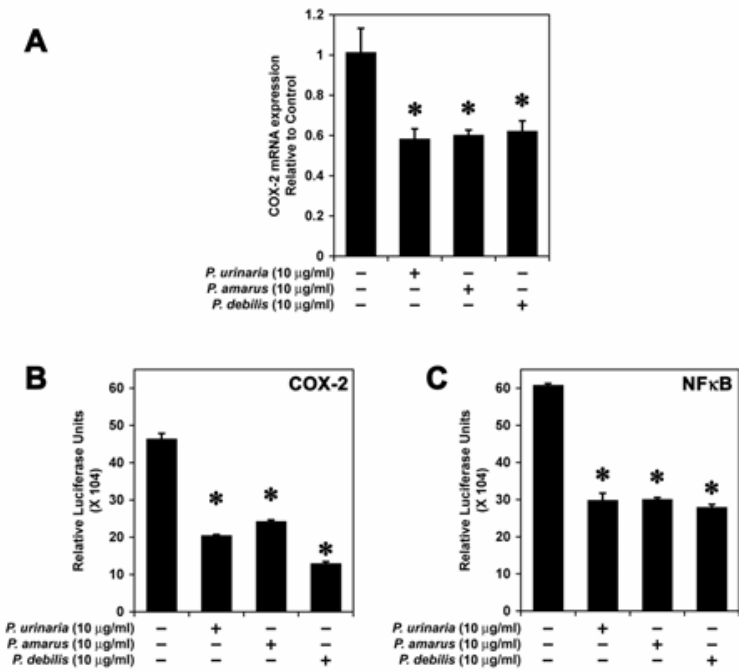

Fig. 2: Phyllanthus extracts inhibit NF-kB activation and COX-2 expression in a transcriptional manner. A. COX-2 expression. HepG2 cells were treated with $10 \mu \mathrm{g} \mathrm{mL}^{-1}$ extracts from $P$. amarus, $P$. urinaria and $P$. debilis and total RNA was isolated and tested for COX-2 mRNA levels by real time RTPCR. All the three extracts decreased the COX-2 mRNA expression compared to the control cells. Data are expressed as fold change in the extract-treated cells compared to the untreated control. * $\mathrm{p}<0.01$. B. Inhibition of COX-2 promoter activity. To determine whether the inhibition in COX-2 expression is in part due to transcriptional suppression, cells were transfected with a plasmid encoding the firefly luciferase under the control of the human COX-2 promoter and the luciferase activity was measured. Luciferase activity is expressed as luciferase light units relative to control, vehicle-treated cells. ${ }^{*} \mathrm{p}<0.01$. C. Inhibition of NF-kB transcriptional activity. COX-2 expression is regulated in part by transcription factor NF-kB. To determine whether Phyllanthus extracts regulated NF-kB transcriptional activity, cells were transfected with a plasmid encoding the firefly luciferase under the control of a NF-kB-responsive promoter and the luciferase activity was measured. Luciferase activity is expressed as luciferase light units relative to control, vehicle-treated cells. ${ }^{*} \mathrm{p}<0.01$

All three extracts reduced COX-2 levels by approximately two-fold compared to untreated cells (Fig. 2A). To confirm that the inhibition occurs at the level of transcription, HepG2 cells were transiently transfected with a plasmid encoding the firefly luciferase reporter gene under the control of the $1.8-\mathrm{kb}$ human COX-2 promoter following which the cells were treated with the three different Phyllanthus extracts. All three extracts significantly inhibited the luciferase activity in the transfected cells when compared to untreated control. P. debilis demonstrated the highest amount of inhibition of promoter activity $(80 \%$ inhibition, $\mathrm{p}<0.01)$, followed by $P$. urinaria $(60 \%$

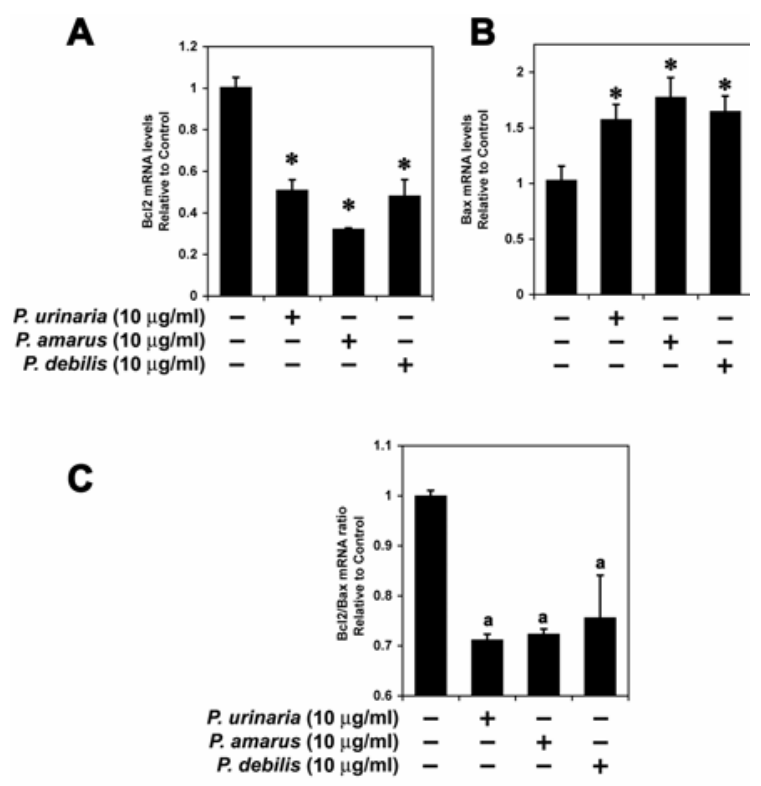

Fig. 3: Phyllanthus extracts inhibits the expression of $\mathrm{Bcl}-2$ while inducing expression of Bax in HepG2 cells. Total RNA from the cells treated with extracts from $P$. amarus, $P$. urinaria and $P$. debilis were tested by RealTime RT-PCR for expression of Bcl2 (A) and Bax mRNA (B). All extracts significantly $(* \mathrm{p}<0.01)$ decreased expression of $\mathrm{Bcl}-2$ mRNA expression and increased that of Bax mRNA expression when compared to the control, vehicle treated cells. $(* \mathrm{p}<0.01)$. Data are expressed as fold change relative to expression in the control vehicle treated cells. All the extracts demonstrated decreased $\mathrm{Bcl}-2 / \mathrm{Bax}(\mathrm{C})$ ratio in the cells treated with the extracts $(a=p<0.05)$

inhibition, $\mathrm{p}<0.01)$ and $P$. amarus $(50 \%$ inhibition, $\mathrm{p}<0.01)$.

COX-2 expression is regulated at the transcriptional level by transcription factor NF-kappaB. Previous studies in hepatocellular carcinoma cells have demonstrated that inhibition of NF-kappaB activation results in decreased COX-2 expression and increased apoptosis $^{[17,18]}$. To determine whether the extracts inhibited NF-kB activity in the cells, the cells were transiently transfected with a plasmid encoding the firefly luciferase reporter gene under the control of a promoter that is activated by NF-kB. All three extracts inhibited NF-kB driven luciferase activity in HepG2 cells (Fig. 2C). Taken together, these data demonstrate that the Phyllanthus extracts induce apoptosis of HepG2 hepatoma cells by inhibiting the transcription of COX-2 gene in part by suppressing the activation of transcription factor NF-kB. 
Effect of the phyllanthus sp. extracts on Bcl2 and Bax gene expression: $\mathrm{Bcl}-2$ family members may regulate mitochondrial death signaling. A high expression of the Bax proteins promotes apoptosis, while a high expression of the Bcl-2 group inhibits apoptosis. In hepatocytes, TNF- $\alpha$ induces apoptosis by the cytochrome $\mathrm{c}$ release and caspase activation, which is mediated by decreased $\mathrm{Bcl}-2$ and $\mathrm{Bcl}-\mathrm{X}_{\mathrm{L}}$ and increased Bid, Bax and $\mathrm{Bak}^{[19]}$. Given the increased apoptosis of the cells following treatment with Phyllanthus extracts suggests a potential role for the Bcl-2 family of proteins in the process. Real time RTPCR analyses revealed decreased levels of the antiapoptotic Bcl-2 mRNA in the cells treated with the Phyllanthus extracts. $P$. urinaria and $P$. debilis inhibited Bcl 2 mRNA expression by approximately 2fold $(\mathrm{p}<0.01)$, while $P$. amarus extracts inhibited the expression by three-fold $(\mathrm{p}<0.01)(\mathrm{Fig} .3 \mathrm{~A})$. In contrast, treatment of the cells the Phyllanthus extracts resulted in increased Bax mRNA (>1.5-fold) levels in the hepatoma cells (Fig. 3B). The ratio of Bcl-2/Bax determines the response to a death signal. $P$. urinaria inhibited $\mathrm{Bcl} 2 / \mathrm{Bax}$ ratio by 0.28 -fold $(\mathrm{p}<0.05)$, while $P$. amarus by 0.25 -fold $(\mathrm{p}<0.05)$ and $P$. debilis by 0.22 fold $(\mathrm{p}<0.05)$ (Fig. $3 \mathrm{C})$. These results provide the first evidence that the apoptosis-related gene products, Bcl-2 and Bax participate in the proapoptotic action mediated by the Phyllanthus extracts on hepatocellular carcinoma cells.

Phyllanthus extracts induces TNF- $\alpha$ mRNA expression while inhibiting IL-8 expression and synergistically increases the TNF- $\alpha$ induced HepG2 cancer cell death: TNF- $\alpha$ is a pleiotropic proinflammatory cytokine that exerts two types of effects through its binding to TNF-receptor 1 or $2^{[20]}$. TNF- $\alpha$ binding to TNFR-1 results in the induction of apoptosis, whereas binding to TNFR-2 potentiates the effect of TNFR-1 induced cell death and promotes inflammatory processes by inducing IL- $8^{[21]}$. Given that the extracts inhibited cell proliferation, we next determined whether they also induce expression of TNF- $\alpha$. All three Phyllanthus extracts inducted TNF- $\alpha$ mRNA expression in the HepG2 cells. While $P$. urinaria extracts induced TNF- $\alpha$ mRNA expression by 3.5 fold $(\mathrm{p}<0.01)$, both $P$. amarus and $P$. debilis extracts induced expression by 4.5 fold $(\mathrm{p}<0.05)$ (Fig. 4A) compared to the untreated control cells.

TNF- $\alpha$ is a potent inducer interleukin-8 (IL-8), a member of the CXC family of chemokines ${ }^{[18]}$. IL- 8 is a pro-inflammatory cytokine and a potent chemotactic agent for neutrophils and induces their lysosomal

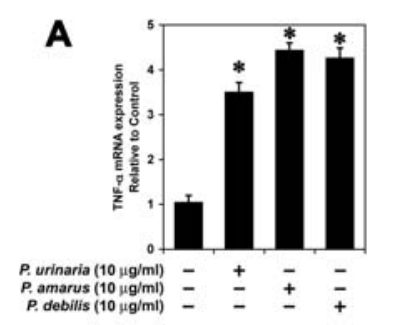

B

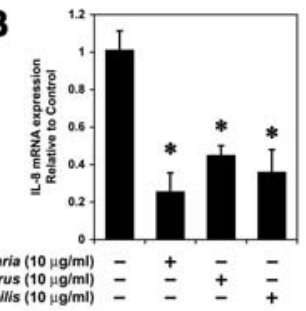

C

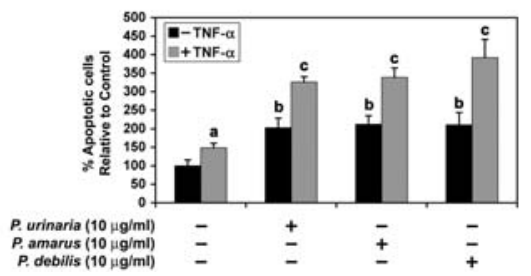

Fig. 4: Effect of Phyllanthus extracts on TNF- $\alpha$ and IL-8 expression and HepG2 cell apoptosis. HepG2 cells were treated with $10 \mu \mathrm{g} \mathrm{mL} \mathrm{mL}^{-1} P$. amarus, $P$. urinaria or $P$. debilis extracts. A. TNF- $\alpha$ mRNA expression. Total RNA was isolated and TNF- $\alpha$ mRNA expression determined by Real time PCR. All three extracts induced expression of TNF- $\alpha$ mRNA when compared to the control, untreated cells. (* $\mathrm{p}<0.01)$. B. IL-8 mRNA expression. Similarly, IL-8 mRNA expression was determined in the cells. All three extracts inhibited IL-8 mRNA expression $(* \mathrm{p}<0.01)$. C. TNF- $\alpha$ and the extracts synergize to induce HepG2 cell apoptosis. The cells were incubated with the Phyllanthus extracts either in the absence or presence of exogenous TNF- $\alpha$ and the level of apoptosis was measured by activation of caspase 3 and 7. Data is represented in percentage of the cells undergoing apoptosis relative to control, untreated cells. The data shows that TNF- $\alpha$ alone had only a modest effect on apoptosis ( $\mathrm{a}$ : $\mathrm{p}=0.01$ compared to untreated controls). Treatment of cells with the extracts alone showed increased levels of apoptosis (b: $\mathrm{p}<0.01$ compared to untreated controls), which was significantly higher in cells, which were also treated with TNF- $\alpha$ (c: $\mathrm{p}<0.01$ compared to the TNF- $\alpha$ alone)

release (contributing to acute inflammatory response $)^{[22]}$. IL-8 is secreted by many cell types, including monocytes, granulocyte and endothelial cells, in response to proinflammatory stimuli such as TNF$\alpha^{[23]}$. TNF- $\alpha$-mediated induction of IL- 8 occurs in part by activating NF-kB ${ }^{[18]}$. The expression of IL-8 correlated with the microscopic vessel invasion HCC tissues. Higher levels of IL-8 were expressed in HCCs at pathologic stage III/IV than in those at stage I/II more relevant to metastatic potential and vessel invasion $^{[24]}$. Downregulation or neutralization of IL-8 inhibited angiogenesis and tumor growth in several tumor models ${ }^{[25,26]}$. Since the Phyllanthus extracts inhibited activation of NF-kB, we next determined whether it affected IL-8 expression. HepG2 cells were treated with the extracts and total RNA was isolated 
and subjected to real time RT PCR. HepG2 cells treated with the $P$. amarus extracts demonstrated a $50 \%$ reduction in the IL-8 mRNA expression $(\mathrm{p}<0.01)$, while those treated with either $P$. debilis or $P$. urinaria demonstrated a $>70 \%$ reduction in IL-8 mRNA expression $(\mathrm{p}<0.01)$ (Fig. 4B). These data imply that the Phyllanthus extracts IL-8 chemokine expression, even though TNF- $\alpha$ expression is induced.

Inhibition of TNF-ainduced IL-8 production results in increased apoptosis of hepatocellular carcinoma cells ${ }^{[18]}$. Given the significant increase in TNF- $\alpha$ levels following treatment of the cells with the extracts, coupled with inhibition of IL-8 expression, we next determined whether this results in increased apoptosis of the cells. Cells treated with $10 \mathrm{ng} \mathrm{mL} \mathrm{m}^{-1} \mathrm{TNF}-\alpha$ alone for 48-h demonstrated a modest increase in apoptosis compared to the untreated controls (Fig. 4C). However, when the cells were treated with the extracts for 48-h there was a significant increase in the number of cells undergoing apoptosis. A two-fold increase in apoptosis was observed in cells treated with extracts from either P. urinaria, P. amarus or $P$. debilis $(\mathrm{p}<0.01)$ (Fig. 4C). Of greater significance was that there was a synergistic increase to over three-fold in cells undergoing apoptosis when they were treated TNF- $\alpha$ and either one of the Phyllanthus extracts $(p<0.01)$ (Fig. 4C). These data suggest that one pathway of inducing apoptosis by extracts from the Phyllanthus species involves induction of TNF- $\alpha$.

\section{CONCLUSION}

Here, we have demonstrated that Phyllanthus extracts decrease cancer cell proliferation and induce apoptosis though induction of TNF- $\alpha$. In addition, the extracts inhibit the expression of proteins involved in protecting the cells from apoptosis including Bcl-2, IL8 and COX-2, while inducing Bax a promoter of apoptosis through mitochondrial depolarization. Our studies also demonstrate that all the three extracts demonstrate potent anti-cancer activity and have the potential as a therapeutic. This is the first demonstration of anti-hepatocellular activity for the three extracts. Further studies, currently underway in the laboratory are necessary to identify the activity ingredient(s) in these extracts that mediate this antiproliferative and proapoptotic activities.

\section{REFERENCES}

1. Lodato, F., G. Mazzella, D. Festi, F. Azzaroli, A. Colecchia and E. Roda, 2006. Hepatocellular carcinoma prevention: A worldwide emergence between the opulence of developed countries and the economic constraints of developing nations. World J. Gastroenterol., 12: 7239-7249.

2. Libbrecht, L., V. Desmet and T. Roskams, 2005. Preneoplastic lesions in human hepatocarcinogenesis. Liver Int., 25: 16-27.

3. Szabo, E., C. Paska, Kaposi Novak, P., Z. Schaff and A. Kiss, 2004. Similarities and differences in hepatitis B and $\mathrm{C}$ virus induced hepatocarcinogenesis. Pathol. Oncol. Res., 10: 5-11.

4. Thyagarajan, S., S. Jayaram, V. Gopalakrishnan, R. Hari, P. Jeyakumar and M. Sripathi, 2002. Herbal medicines for liver diseases in India. J. Gastroenterol. Hepatol., 17 (Suppl. 3): S370-S376.

5. Aggarwal, R., U.C. Ghoshal and S.R. Naik, 2002. Treatment of chronic hepatitis B with interferonalpha: cost-effectiveness in developing countries. The Natl. Med. J. India, 15: 320-327.

6. Yalcin, K., H. Degertekin, C. Yurdaydin, M. Bozdayi and H. Bozkaya, 2003. The role of $\mathrm{HBeAg}$ seroconversion in acute exacerbation of liver disease with termination of hepatitis $\mathrm{B}$ and $\mathrm{D}$ virus infection in a chronic hepatitis $\mathrm{D}$ patient during alpha-interferon therapy. Eur. J. Gastroenterol. Hepatol., 15: 819-823.

7. Enjoji, M., S. Morizono, K. Kotoh, M. Kohjima, Y. Miyagi, T. Yoshimoto and M. Nakamuta, 2005. Re-evaluation of antitumor effects of combination chemotherapy with interferon-alpha and 5fluorouracil for advanced hepatocellular carcinoma. World J. Gastroenterol., 11: 5685-5687.

8. Thyagarajan, S.P., S. Jayaram, T. Valliammai, N. Madanagopalan, V.G. Pal and K. Jayaraman, 1990. Phyllanthus amarus and hepatitis B. Lancet, 336: 949-950.

9. Blumberg, B.S., I. Millman, P.S. Venkateswaran, and S.P. Thyagarajan, 1990. Hepatitis B virus and primary hepatocellular carcinoma: Treatment of HBV carriers with Phyllanthus amarus. Vaccine, 8: (Suppl.): S86-92. 
10. Mehrotra, R., S. Rawat, D.K. Kulshreshtha, P. Goyal, G.K. Patnaik and B.N. Dhawan, 1991. In vitro effect of Phyllanthus amarus on hepatitis $B$ virus. The Indian J. Med. Res., 93: 71-73.

11. Zoulim, F., 1999. Therapy of chronic hepatitis B virus infection: inhibition of the viral polymerase and other antiviral strategies. Antiviral Res., 44: 130 .

12. Blumberg, B.S., I. Millman, P.S. Venkateswaran and S.P. Thyagarajan, 1989. Hepatitis B virus and hepatocellular carcinoma--treatment of $\mathrm{HBV}$ carriers with Phyllanthus amarus. Cancer Detect. Prev., 14: 195-201.

13. Kiemer, A.K., T. Hartung, C, Huber and A.M. Vollmar, 2003. Phyllanthus amarus has antiinflammatory potential by inhibition of iNOS, COX-2 and cytokines via the NF-kappaB pathway. J. Hepatol., 38: 289-297.

14. Calixto, J.B., A.R. Santos, V. Cechinel Filho and R.A. Yunes, 1998. A review of the plants of the genus Phyllanthus: Their chemistry, pharmacology and therapeutic potential. Med. Res. Rev., 18: 225258.

15. Lee, C.Y., W.H. Peng, H.Y. Cheng, F.N. Chen, M.T. Lai and T.H. Chiu, 2006. Hepatoprotective effect of Phyllanthus in Taiwan on acute liver damage induced by carbon tetrachloride. Am. J. Chinese. Med., 34: 471-482.

16. Leng, J., C. Han, A.J. Demetris, G.K. Michalopoulos and T. Wu, 2003. Cyclooxygenase2 promotes hepatocellular carcinoma cell growth through Akt activation: evidence for Akt inhibition in celecoxib-induced apoptosis. Hepatology, 38: 756-768.

17. Kern, M.A., A.M. Haugg, A.F. Koch, T. Schilling, K. Breuhahn, H. Walczak, B. Fleischer, C. Trautwein, C. Michalski, H. Schulze-Bergkamen, H. Friess, W. Stremmel, P.H. Krammer, P. Schirmacher and M. Muller, 2006. Cyclooxygenase-2 inhibition induces apoptosis signaling via death receptors and mitochondria in hepatocellular carcinoma. Cancer Res., 66:70597066.

18. Osawa, Y., M. Nagaki, Y. Banno, D.A. Brenner, T. Asano, Y. Nozawa, H. Moriwaki and S. Nakashima, 2002. Tumor necrosis factor alphainduced interleukin-8 production via NF-kappaB and phosphatidylinositol 3-kinase/Akt pathways inhibits cell apoptosis in human hepatocytes. Infect. Imm., 70: 6294-6301.
19. Ghavami, S., M. Hashemi, K. Kadkhoda, S.M. Alavian, G.H. Bay and M. Los, 2005. Apoptosis in liver diseases--detection and therapeutic applications. Med. Sci. Monit., 11: RA337-345.

20. Warren, G.L., T. Hulderman, N. Jensen, M. McKinstry, M. Mishra, M.I. Luster and P.P. Simeonova, 2002. Physiological role of tumor necrosis factor alpha in traumatic muscle injury. FASEB J., 16: 1630-1632.

21. Chen, X., K. Kandasamy and R.K. Srivastava, , 2003. Differential roles of RelA (p65) and c-Rel subunits of nuclear factor kappa $B$ in tumor necrosis factor-related apoptosis-inducing ligand signaling. Cancer Res., 63: 1059-1066.

22. Erger, R.A. and T.B. Casale, 1995. Interleukin- 8 is a potent mediator of eosinophil chemotaxis through endothelium and epithelium. Am. J. Physiol., 268: L117-122.

23. Shi, X.Z. and S.K. Sarna, 2005. Transcriptional regulation of inflammatory mediators secreted by human colonic circular smooth muscle cells. Am. J. Physiol., 289: G274-284.

24. Kubo, F., S. Ueno, K. Hiwatashi, M. Sakoda, K. Kawaida, K. Nuruki and T. Aikou, 2005. Interleukin 8 in human hepatocellular carcinoma correlates with cancer cell invasion of vessels but not with tumor angiogenesis. Ann. Surg. Oncol., 12: 800-807.

25. Arenberg, D.A., S.L. Kunkel, P.J. Polverini, M. Glass, M.D. Burdick and R.M. Strieter, 1996. Inhibition of interleukin-8 reduces tumorigenesis of human non-small cell lung cancer in SCID mice. J. Clin. Invest., 97: 2792-2802.

26. Moore, B.B., D.A. Arenberg, K. Stoy, T. Morgan, C.L. Addison, S.B. Morris, M. Glass, C. Wilke, Y.Y. Xue, S. Sitterding, S.L. Kunkel, M.D. Burdick and R.M. Strieter, 1999. Distinct CXC chemokines mediate tumorigenicity of prostate cancer cells. Am. J. Pathol., 154: 1503-1512. 